\title{
Simulating the Thermal-Energy Performance of Buildings at the Urban Scale: Evaluation of Inter- Building Effects in Different Urban Configurations
}

\author{
Anna Laura Pisello, Veronica Lucia Castaldo, Tiziana Poli and Franco Cotana
}

\begin{abstract}
The reduction of the energy use of buildings at the urban scale represents a key research and design topic with the purpose of developing specific methods for saving energy in buildings. These methods are often focused on the analysis of building thermalenergy behavior by considering the building as a stand-alone object. In this per-spective, the thermal-energy behavior of two buildings in New York City is evaluated in this paper with varying urban contexts, in order to evaluate the Inter-Building Effect (IBE). The IBE analysis shows that the inaccuracy in neglecting the urban context in building modeling varies from 9.6 percent, to 71.9 percent. These results confirm that, in order to make accurate predictions about building thermal-energy performance in real urban contexts through dynamic simulation, the interaction between the building and the urban surrounding should be taken into account, in particular in dense urban areas.
\end{abstract}

KEYWORDS inter-building effect; urban context; building thermal-energy dynamic simulation; building energy performance; mutual shading

\section{Introduction}

The issue of analyzing the complex relationship among buildings in terms of thermal-energy behavior at an urban scale has become increasingly important for both designers and researchers, considering the large amount of energy consumed by buildings and the huge environmental sustainability issue related to the construction sector. Several sustainable development indicators have been proposed by Berardi (2012), who introduced different rating systems for the evaluation of building energy requirements by considering, first, the buildings separately, and, second, the buildings all together, as a whole. In fact, the global contribution of build-ings to total energy consumption has increased to 40 percent of the total energy requirement (Perez et al., 2008); moreover, a strong increase in urban populations has been predicted by 2050 (US Green Building Council, 2011), with a consequent expected variation of urban morphology and density. Due to this expected mutation, the elaboration of a rigorous method for the energy assessment of buildings located inside the urban context has become a key research issue (Rossi et al., 2014).

Therefore, the research presented in this paper deals with the investigation of the energy performance of two buildings' configurations: first, concerning the

Correspondence Address: Anna Laura Pisello, CIRIAF - University of Perugia. Via Duranti, 06125 - Perugia, Italy. E-mail: pisello@crbnet.it. 
individual buildings (stand-alone configuration) and, second, investigating the same buildings within their urban context, in order to assess the impact of the "Inter-Building Effect-IBE" (Pisello et al., 2012a) on energy performance. The IBE index represents a parameter aimed at quantifying the effect of the mutual influence and interaction of adjacent buildings in terms of year-round energy performance. In this perspective, the purpose of this paper is to quantify the error in predicting energy requirements that may derive from considering the building as a non-realistic, stand-alone object rather than the same building in its urban neighborhood, even if the analysis is carried out, in both the case, by sophisticated dynamic simulation tools (Crawley et al., 2001). In fact, it was demonstrated (Pisello et al., 2014) that effects attributable to the mutual interaction among buildings can become very significant in terms of energy dynamics; thus they cannot be neglected while accurately predicting buildings' energy use in an urban context. Additionally, starting from these results, this research analyzes the Inter-Building Effect at different levels of urban density.

\section{Background and Objectives}

During the last decade, several research efforts were carried out to investigate the interaction between buildings and their surrounding environment (Steemers, 2013). Important research evaluated the effect of the local outdoor thermal conditions on the energy performance of buildings and their results showed that it is necessary to consider the local boundary conditions in addition to the buildings' features (He et al., 2009) for predicting realistic building energy behavior.

Other studies were performed also in order to evaluate peculiar urban climate phenomena affecting buildings' thermal-energy performance, i.e. Urban Heat Island (Memon et al., 2008), as a result of the sprawling urbanization and the consequent increase of emissions and pollutants' concentration in dense urban areas. To this aim, Akbari et al. (1997) estimated the impact of local-scale climate variations on actual buildings' energy performance by monitoring and simulating several buildings in Sacramento, CA. Hassid (Hassid et al., 2000), moreover, investigated the effect of summer heat islands in the western part of Athens on cooling energy demand and peak power, via building energy dynamic simulation. Rosenfeld et al. (1995) evaluated both building-scale and city-scale effects of the increased temperature, typical of urban heat islands, and the consequent increase in cooling energy use.

Together with the growing investigation of urban phenomena, energy costs in recent years has led to the development of sophisticated techniques for assessing the energy consumption and indoor air quality of urban buildings (Pisello and Cotana, 2014). In particular, dynamic simulation tools allowed researchers to make reliable predictions about the energy behavior and environmental impact of buildings from the early stage of the design (Crawley et al., 2008). On the other hand, Ambrosone et al. (1983) developed a method for modeling buildings in order to assess their global behavior through the aggregation of different blocks. Pisello et al. (2012b) developed an innovative method to integrate architectural design, dynamic simulation, experimental campaign, and sensitivity analysis for optimization.

The increasing affordability of these simulation tools also guided other researchers to develop rigorous models aimed at evaluating the energy performance of buildings within their surrounding environment, focusing attention on both the environmental impact of buildings and the impact of surrounding 
areas on the energy performance of buildings. Therefore, Dalamagkidis and Kolokotsa (2008) studied the overall "environmental control" of buildings and emphasized the importance of the implementation of "intelligent control techniques" to monitor all the factors responsible for a building's sustainability in terms of thermal comfort, visual comfort, air quality, and energy conservation. To this same purpose, the research by Morello et al. (2009) demonstrated the important role that urban design and urban configurations play in the performance of individual buildings. This same contribution consisted of the elaboration of specific tools to quantify the impact of the urban morphology in determining buildings' energy balance. The study provided preliminary analysis procedures for urban planning, comparative energy assessment, and building performance optimization. Additionally, Ratti et al. (2003) implemented an integrated approach to analyzing the energy performance of buildings in the urban context through innovative techniques for urban analysis based on raster image processing. Moreover, Heiselberg et al. (2007) elaborated sensitivity analyses to identify the most important parameters related to the building-performance optimization at the early stage of the design process.

In the same panorama, P.J. Jones et al. (2001) emphasized the importance of con-sidering buildings as part of an urban neighborhood, affecting the thermalenergy performance of the neighborhood. They proposed the "Energy and Environment Prediction" (EEP) model using a GIS platform for predicting the energy consump-tion and environmental impact of a neighborhood network of buildings. These new modeling approaches considered buildings in an urban environment defined by the presence of other buildings (Pisello et al. (2012a). The existence of these other build-ings must be taken into consideration when investigating a building's energy requirements. The error in determining the thermal-energy behavior of those build-ings is not negligible in several climate contexts, both in summer and winter conditions. Therefore, they developed a method for evaluating buildings' energy performance by enlarging the perspective from the perspective of an individual building to a network of buildings, by calculating the Inter-Building Effect (IBE) extent in terms of primary energy requirement for heating and cooling.

Capeluto and Shaviv (2001), therefore, investigated buildings' mutual influence in terms of availability of sunlight. They proposed a model for the calculation of urban density to show that the modification of the urban layout may produce important variation in the availability of natural light even in a very dense urban context. Further investigations about this issue were carried out by Golany (1996), who identified a set of rules about the orientation of streets, the geometry of the buildings, and the urban proportions in order to achieve the best coupled insideoutside comfort conditions, especially in terms of the day-lighting optimization.

Later on, the complex relationship existing between the energy requirements of buildings and their occupancy at inter-building levels was also investigated, by simulating the impact of a peer network on the energy use of the buildings. In particular, Xu et al. (2011) developed an integrated, inter-building physical and human network model in order to predict the energy conservation potential for an assumed urban block. Furthermore, in order to accurately simulate the energy consumption of users in peer networks when they are exposed to ecofeedback systems, Chen et al. (2013) proposed a new random network model by agent-based simulation, in order to emulate the energy consumption of users in peer networks when they are exposed to eco-feedback. In this perspective, by implementing the important research developments in building physics, urban 
design, and in the complex relationship between buildings and their surroundings, the purpose of this work is to study the inter-building phenomenon with varying urban configurations. To this end, the dynamic simulation of two buildings is carried out in both the "stand-alone" configuration and inside an urban context. Different urban configurations are also modeled, to investigate the corresponding Inter-Building Effect extent with varying urban morphologies. Buildings' energy dynamics are here evaluated in real neighborhoods with realistic climate conditions, in order to precisely define how the whole urban network affects energy predictions for buildings and, therefore, to demonstrate the strong impact of urban morphology on the energy assessment of buildings in terms of the Inter-Building Effect.

\section{Methodology for Assessing a Building's Energy Needs in an Urban Context}

In order to evaluate the difference in the energy performance of individual buildings compared to those same buildings considered inside their urban network, two real buildings were selected in the city of New York: an office building and a residential building. The goal was to simulate energy consumption in buildings that had different uses but equivalent technical and architectural features, in order to evaluate the influence of the urban surrounding, i.e., IBE, in buildings characterized by different occupants and different control systems.

The first stage consisted of evaluating the urban context, analyzing the buildings' architecture, and assessing the buildings' energy plants and construction materials. This information constituted the input data for the elaboration of a realistic model to be simulated within the Energy Plus dynamic simulation environment (Crawley et al., 2001). Then, the dynamics of the two buildings in the two different configurations, i.e. as "stand-alone object" and within the "urban network," were simulated, in order to quantify the IBE (Inter-Building Effect) index, in terms of primary energy requirements for heating and cooling in the two buildings. Therefore, as input parameters for the analysis, the real geometry and construction technology of the two buildings were considered, in addition to the real HVAC systems and occupancy schedule of each thermal zone. All this information was collected during a preliminary energy audit of the buildings where architectural and technical plants were investigated. According to these detailed input data, final results concerning the primary energy requirements of the buildings for both heating and cooling were obtained through the year-round dynamic simulation of the thermal-energy performance of the buildings, in terms of primary energy requirements.

Additionally, the analysis was extended to determine the inter-building mutual impact in terms of variation of indoor operative temperature and solar gains through windows in several days during the course of the year. The same comparison was then similarly performed by considering only the "lower floors" of each building, in order to estimate the maximum registered IBE.

The second part of the study consisted of the evaluation of the effect of the urban morphology and the density of the construction on the buildings' thermalenergy behavior. To this end, three different neighborhoods in New York City, representing different levels of urban density, were modeled and simulated in terms of urban geometry. Finally, the Inter-Building Effect was calculated for each of the three different urban configurations. 


\section{Dynamic Thermal-Energy Simulation}

Both annual and daily dynamic simulations of the case study buildings were performed by taking into account both architectural and technical features of the buildings.

Therefore, both the real buildings' HVAC systems and internal loads for appliances were taken into account, by considering technical plants and occupancy of the buildings. Occupancy energy use was estimated by considering an occupancy level of 0.5 persons per $\mathrm{m}^{2}$ and additional heat gains due to the presence of generic equipment (i.e., fridges, lamps, computers) from about 12 to 30 $\mathrm{W} / \mathrm{m}^{2}$, depending on the considered thermal zone. As regards the HVAC systems, mechanical ventilation providing $3 \mathrm{vol} / \mathrm{h}$ was modeled, together with a gas-fire condensing boiler and fancoil units. The systems were on from 08.00 to 18.00 five days a week in the office building ("B1"). As regarding the residential building ("B2"), the user's profile was slightly different as it considered the systems on from 07.00 to 22.00 , and internal gains of $3.5 \mathrm{~W} / \mathrm{m}^{2}$ and $30 \mathrm{~W} / \mathrm{m}^{2}$, for bedrooms and kitchens, respectively. The building's infiltrations value was set around $0.7 \mathrm{vol} / \mathrm{h}$.

The envelope characterization in the simulation engine was carried out by describing each layer material, as observed in the technical plants and reported in the following "Description of the case study" section. The final thermal transmittance and internal heat capacity values were calculated by following the technical prescriptions provided in BS EN ISO 6946 (BS EN ISO 6946:2007). In particular, opaque wall thermal transmittance corresponds to $0.35 \mathrm{~W} / \mathrm{m}^{2} \mathrm{k}$, and internal heat capacity of the same walls corresponds to $88.2 \mathrm{~kJ} / \mathrm{m}^{2} \mathrm{k}$.

The climate file used for the energy simulation was the TMY file (Oko and Ogoloma, 2011) of New York City, JFK, which takes into account the hourly characteristics of the city weather and climate boundary conditions, by referring to the data provided by the weather station located at the John Fitzgerald Kennedy Airport (JFK). The real orientation and position of the buildings and their actual geographic locations were also taken into account.

\section{Inter-Building Effect Calculation}

After using dynamic simulation to analyze the considered scenarios, i.e. single buildings and networks of buildings in varying urban density contexts, the Inter-Building Effect was estimated, by analyzing the difference between the two scenarios in terms of indoor thermal behavior and primary energy requirements for heating and cooling.

The IBE index calculation was performed following the procedure proposed by Pisello et al. (2012a), on both monthly and annual bases, for each urban density level and for each case study building. The calculation was carried out by (eq.1) as follows:

$$
\mathrm{IBE}_{K}=\frac{\sum_{i=1}^{w} \frac{\mathrm{PE}_{N, i}-\mathrm{PE}_{S, i}}{\mathrm{PE}_{S, i}}}{w} \cdot 100 \quad[\%]
$$

where:

- K: index of neighborhood type;

- w: number of months in which the index is evaluated; 
- PEN,i: primary energy demand for heating and cooling in the case of the building within the urban network ("N" configuration);

- PES, $i$ : primary energy demand for heating and cooling in the case of building considered as "stand-alone" ("S" configuration).

As previously mentioned, the IBE index was conceived so that the further the index is from zero, the greater is the error in determining the building energy requirement if each building is modeled as a stand-alone object rather than within the urban network.

\section{Description of the Case Study}

The Buildings. The proposed methodology was applied to two different existing buildings located Midtown Manhattan, New York City, within the "Worldwide Plaza" complex (See Figure 3.). This complex consists of two main buildings: the "One Worldwide Plaza" and the "Two Worldwide Plaza," which are two skyscrapers of the Post-modern architectural school, designed by David Childs of Skidmore, Owings \& Merrill, and completed in 1989. The first building (B1) is a 50-floor office building, $237.14 \mathrm{~m}$ high; the second skyscraper (B2) is a 38-floor residential building, $119 \mathrm{~m}$ high (See Figures 1 and 2).

After the definition of the orientation and the geographical positioning of the two buildings, situated at a latitude of $40^{\circ} 45^{\prime} 4293^{\prime \prime}$ and longitude of $73^{\circ} 59^{\prime} 0558^{\prime \prime}$ at about $16 \mathrm{~m}$ above sea level, the architectural and technical features of both the buildings were investigated. They both are characterized by a "sandwich" panel envelope, consisting of (i) an outer layer of bricks $(0.08 \mathrm{~m})$, (ii) an insulation panel of XPS $(0.08 \mathrm{~m})$, (iii) concrete blocks $(0.10 \mathrm{~m})$, and (iv) internal gypsum plasterboard $(0.01 \mathrm{~m})$. As far as the windows are concerned, both of the buildings are characterized by a simple double glazing system $(3+13+6 \mathrm{~mm})$ with an air filled camera and aluminum frames. Given the real occupancy schedule of the two buildings, open space offices in B1 and apartments in B2 were modeled. A main lobby was also modeled in both the buildings at the ground floor; moreover,

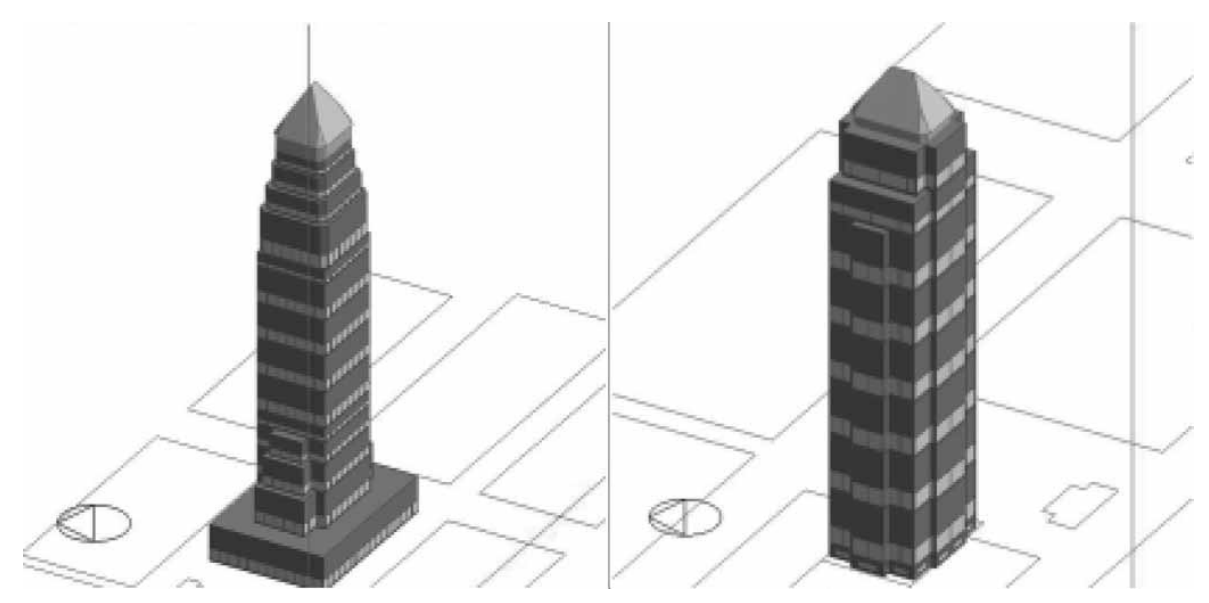

Figures 1 and 2: Models of the two case study buildings: (Left) The office building (B1).

(Right) The residential building (B2). 


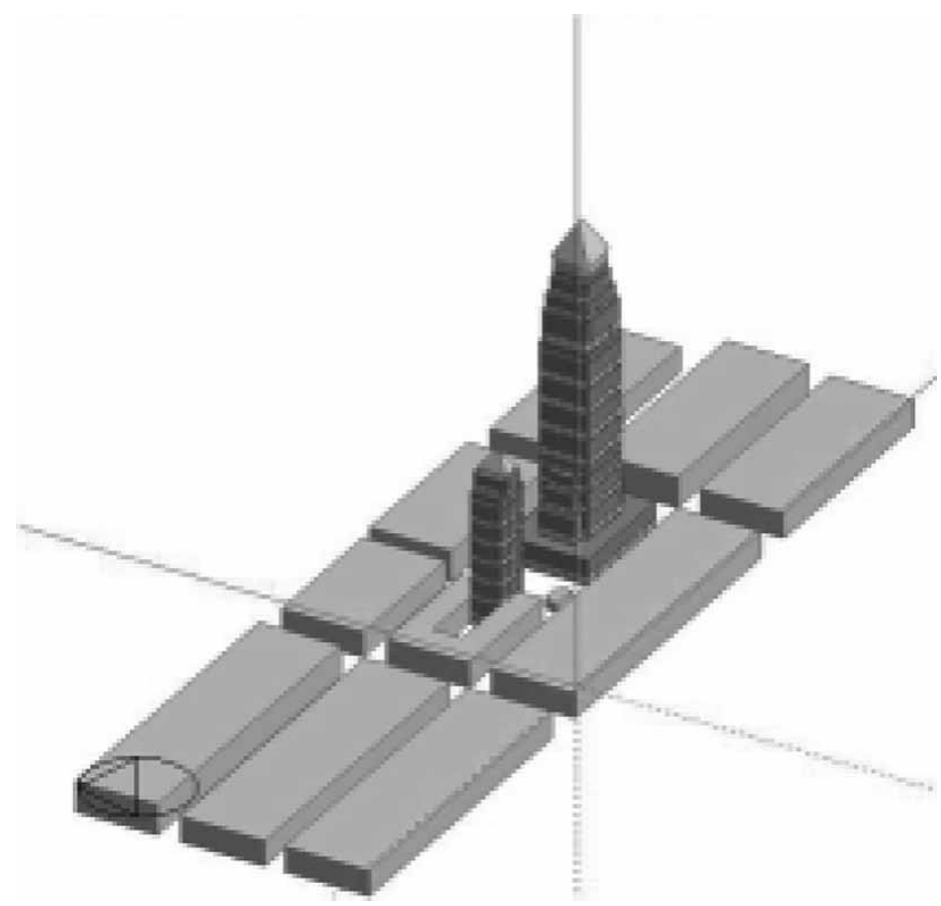

Figure 3: Schematic layout of the real neighborhood, where the "Worldwide Plaza" complex is located.

the areas directly adjacent to the roofs were not considered as "thermal zones" in both the simulation models.

The Urban Neighborhoods. In order to estimate the impact of the urban morphology on predictions of energy consumption, three realistic urban configurations were taken into account. Therefore, in addition to the original model of the neighborhood where the case studies are located, two other models of neighborhoods were simulated through the same methodology. In particular, Hell's Kitchen, which is the case studies' effective neighborhood, represented the "intermediate" urban density level in this study. The other two models consisted of: a neighborhood characterized by low-rise buildings in Soho (about 20-25 m), in order to characterize the traditional Downtown Manhattan district; and a neighborhood with very high-rise buildings (about 150-200 m), as the traditional skyscrapers' district in Midtown Manhattan (See Figures 4 and 5).

\section{Discussion of the Results}

\section{Daily Thermal-Energy Assessment}

The simulations were performed for the two case study buildings within the three considered neighborhoods in order to compare the "stand-alone" with the "building-network" conditions. The operative temperature, the sensible heating and cooling requirement, and the solar gains through the windows were chosen as the main parameters to investigate the IBE. For daily analysis, representative days for each season were selected: January 21 for winter, April 21-22 for 


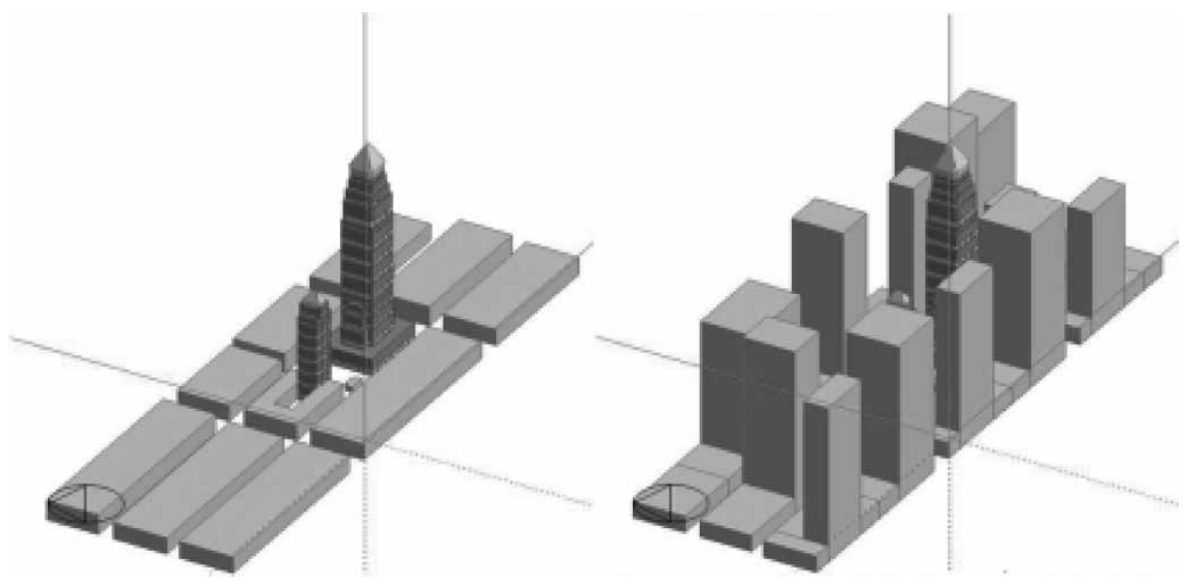

Figures 4 and 5: Models of the two neighborhoods evaluated: (Left) Soho, Downtown Manhattan; (Right) Theater District, Mid-Town Manhattan, New York City.

spring, July 21-22 for summer and October 21 for fall climate conditions. The analysis of the daily profile of indoor operative temperature showed how the two cases of stand-alone buildings and buildings inside the urban network present important differences, up to $2.5^{\circ} \mathrm{C}$, around noon and first afternoon, i.e., when solar radiation has the main impact on indoor thermal performance (See Figures 6(a) and (b)). Focusing the attention to the only lowest floors, this same difference is even higher, and its maximum value $\left(4.8^{\circ} \mathrm{C}\right)$ is registered for B2 in fall (See Figures 7(a) and (b)).

The evaluation of solar gains through the external windows showed impor-tant discrepancies between the two simulated scenarios (i.e. " $\mathrm{S}$ " and " $\mathrm{N}$ " configuration). In fact, the solar gains are greater in the case of the "stand-alone" building rather than the case of the same building surrounded by adjacent buildings, which represent a sort of physical shading, with even higher effects at lower floors. In particular, the maximum difference is about 24 percent ( $339 \mathrm{kWh}$ ) on July 21 for B1 and 77 percent $(260 \mathrm{kWh})$ on October 21 for B2. For what concerns the lower floors, the difference in terms of solar gains between the two configurations corre-
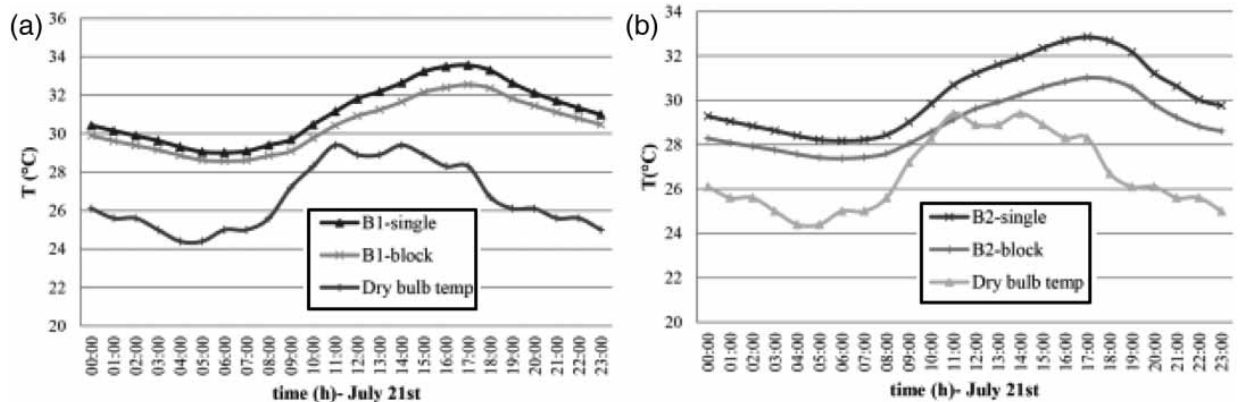

Figures 6 (a) and (b): Indoor thermal-energy analysis of the two buildings;(Left) the office one (B1) and (Right) the residential one (B2), considered as a whole, for the months of July. Comparison between the stand-alone ("single") and the urban network case ("block") in terms of trend of indoor operative temperature. 

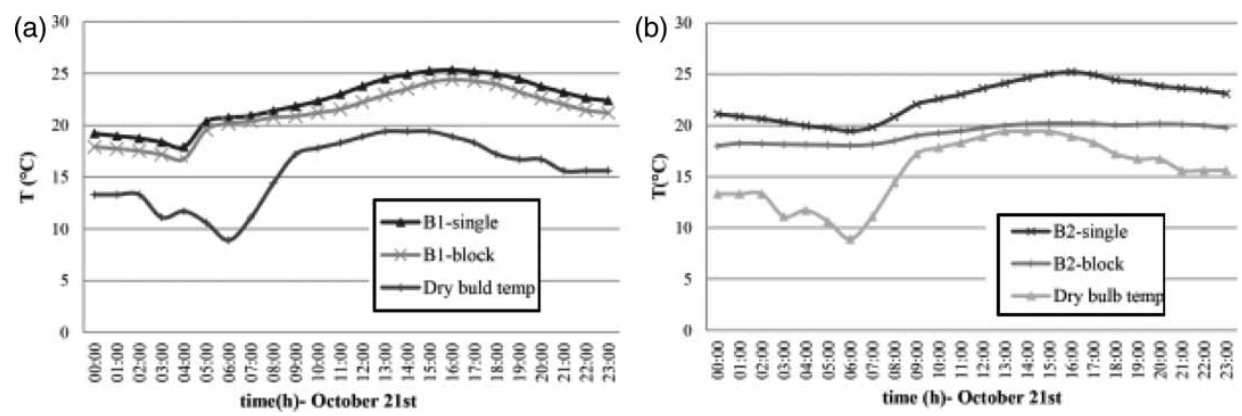

Figures 7 (a) and (b): Indoor thermal-energy analysis of the two buildings: (Left) the office one (B1) and (Right) the residential one (B2), referring only to the lower floors, for the month of October. Comparison between the stand-alone ("single") and the urban network case ("block") in terms of trend of indoor operative temperature.

sponds to 75 percent $(69.5 \mathrm{kWh})$ on October 22 and 78 percent $(55.3 \mathrm{kWh})$ on July 21, for B1 and B2, respectively.

The result of the dynamic simulations concerning a south-facing thermalzone located at the 5th floor of each building were then analyzed. The solar gains through the external windows are shown. The analysis showed that on a typical winter day (January 20), when the sun height is lower, the impact of surrounding buildings in terms of shading effect is even higher than during the summer (July 20), despite the more powerful radiation extent registered in summer. The peaks found for January (See Figures 8(a), (b), (c), and (d)) were generated by the fact that the building has two main groups of windows: the first faces
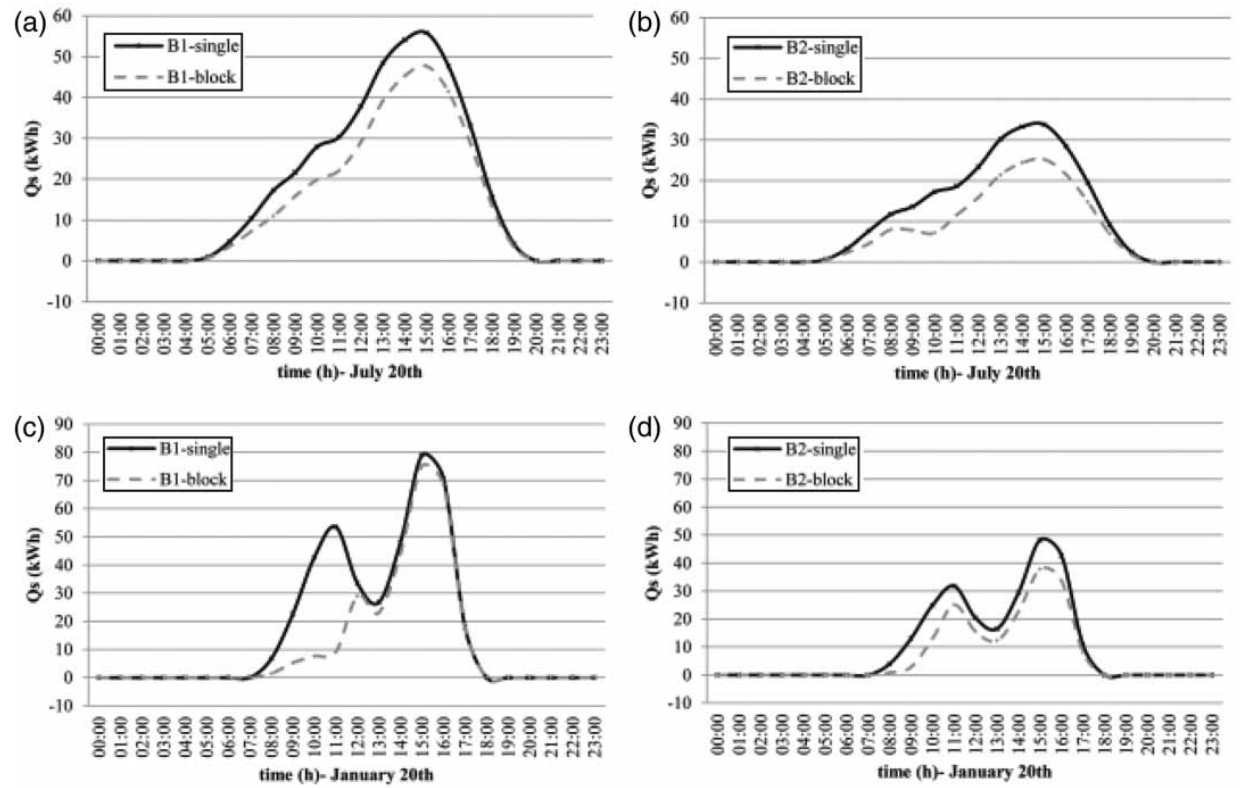

Figures 8 (a), (b), (c), (d): Analysis of a south-facing thermal zone situated at the 5th floor of each building; (Left) the office one (B1) and (Right) the residential one (B2), for the months of January and July. Comparison between the stand-alone ("single") and the urban network scenario ("block") in terms of solar gains through the external windows. 
southeast and the other, which faces southwest, is shaded by nearby buildings in the winter when the sun strikes at a lower height. In summer, solar radiation is consistent during the course of the day because of the high intensity of the diffuse solar radiation. The shading from the surrounding buildings located in the southeast occurs in the morning, while the shading from adjacent buildings southwest occurred during the afternoon. In particular, the presence of the skyscraper on the southeast side of B1 makes this building more affected by the IBE phenomenon.

In order to evaluate the energy performance of the case study buildings, the analysis of the energy requirement for heating and cooling from the "New York City Department of Housing Preservation \& Development" (www.nyc.gov) is here examined to determine the heating and cooling period in Manhattan, NY. This document reports that, in general, the heating equipment is not operative from June to September, while the cooling system is not operative from October to April. Therefore, the collected results concern the operative system period for both energy systems.

The results showed that, in terms of cooling and heating requirements, the performance of the two buildings differ up to $155 \mathrm{kWh}$ (7 percent) in terms of primary energy requirements for heating registered on January 21 (See Figure 9a.) for the office building (B1), and up to $43.5 \mathrm{kWh}$ (18 percent) on January 21 for the residential building (B2) (See Figure 9b). On the other hand, by considering only the lower floors, an even more important difference is found: the Inter-Building Effect corresponds to 168 percent (at 09.00) and 298 percent (at 06.00) on October 21, for B1 and B2 respectively (See Figures 9c and 9d). Also, the analysis of the primary energy requirements for cooling showed significant
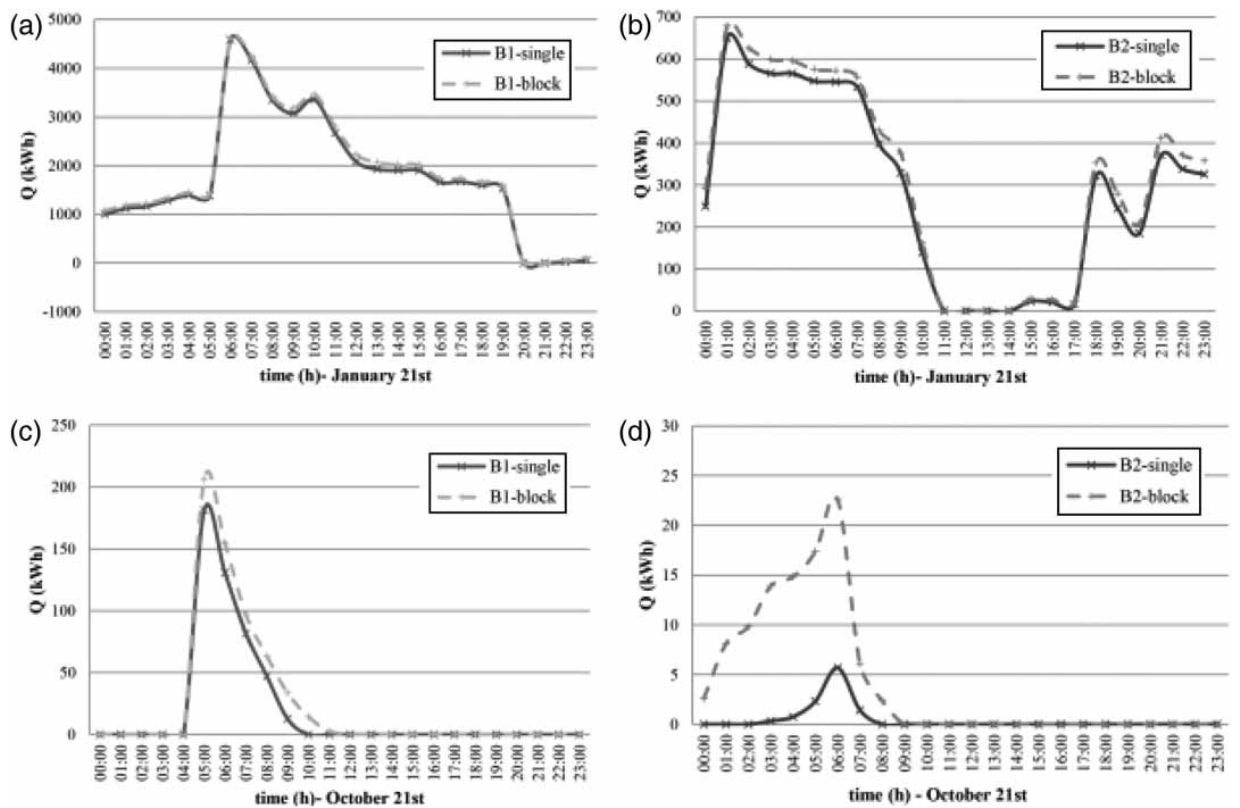

Figures 9 (a), (b), (c), (d): Energy analysis of the two buildings; (Left) the office one (B1) and (Right) the residential one (B2), considered as a whole (9a/9b) and by referring only to the lower floors (9c/9d), for the months of January and October. Comparison between the stand-alone ("single") and the urban network case ("block") in terms of trend of the sensible heating provided (kWh). 
differences between the stand-alone buildings and the same buildings inside the urban network. The energy requirement varies up to $359 \mathrm{kWh}$ (28 percent) on July 22nd for B1 and up to $68 \mathrm{kWh}$ (31 percent) on July 21 for B2 (See Figures 10a and $10 \mathrm{~b})$. In fact, in July, and in summer conditions in general, the primary energy requirement for cooling is higher for the stand-alone building rather than within the urban context, because there is no shading from adjacent buildings. In fact, cooling requirements are higher in the case of stand-alone buildings, with differences of 34 percent and 58 percent on July 21 for the two buildings. Additionally, consistently with respect to the previous findings, the lower floors of B1 and B2 show that the primary energy for heating is higher in the case of the buildings inside their urban network.

\section{Inter-Building Effect of the Real Neighborhood}

The analysis of the Inter-Building Effect is now carried out through the evaluation of the energy performance of the case studies. In particular, the primary energy requirement for heating and cooling is taken into account on both a daily and an annual basis. As expected, the differences are also visible in terms of building energy performance; in fact, the main results show that the primary energy requirement for heating presents lower discrepancy between the two scenarios, with respect to the primary energy requirements for cooling (See Figures 11(a) and (b)). This seasonal variation is mainly due to the extent of solar radiation during summer months. This means that the mutual shading, produced by the presence of close buildings taken into account through the IBE analysis, has a relatively higher impact.
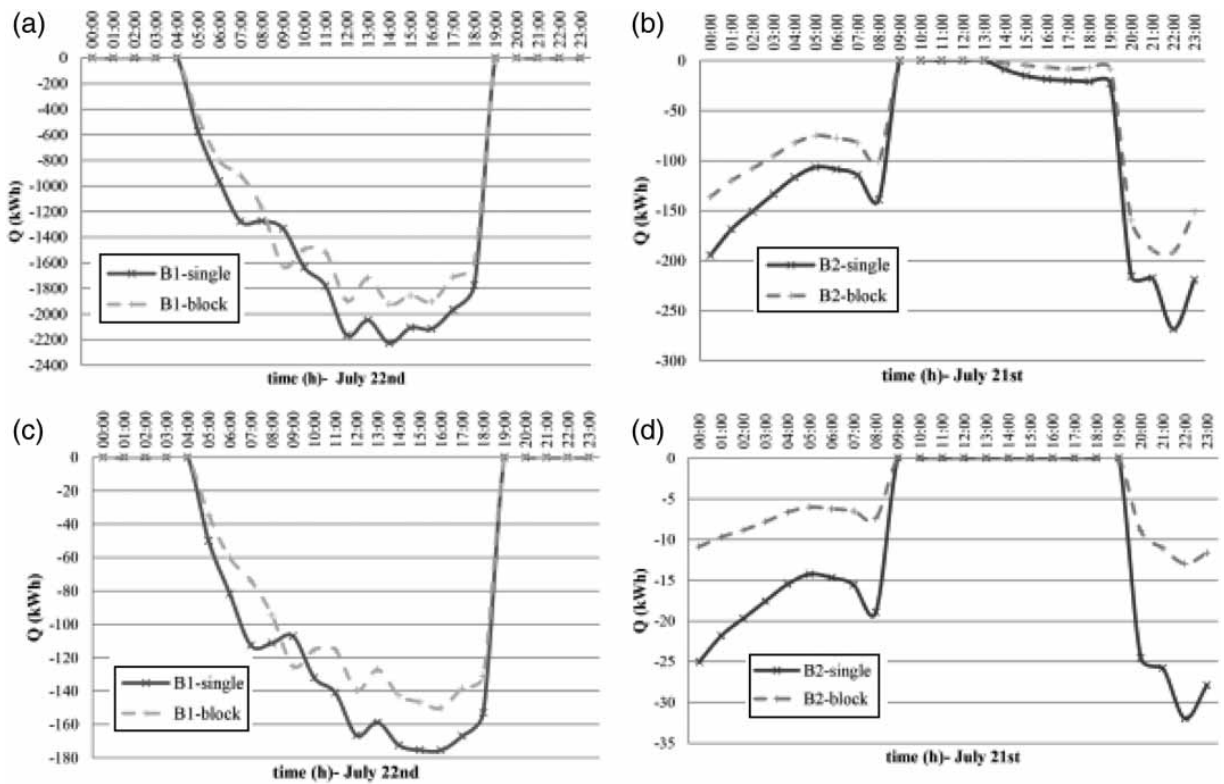

Figures 10 (a), (b), (c), (d): Energy analysis of the two buildings; (Left) the office one (B1) and (Right) the residential one (B2), considered as a whole (10a/10b) and by referring only to the lower floors (10c/ $10 \mathrm{~d}$ ), for the month of July. Comparison between the stand- alone ("single") and the urban network case ("block") in terms of trend of the sensible cooling provided (kWh). 

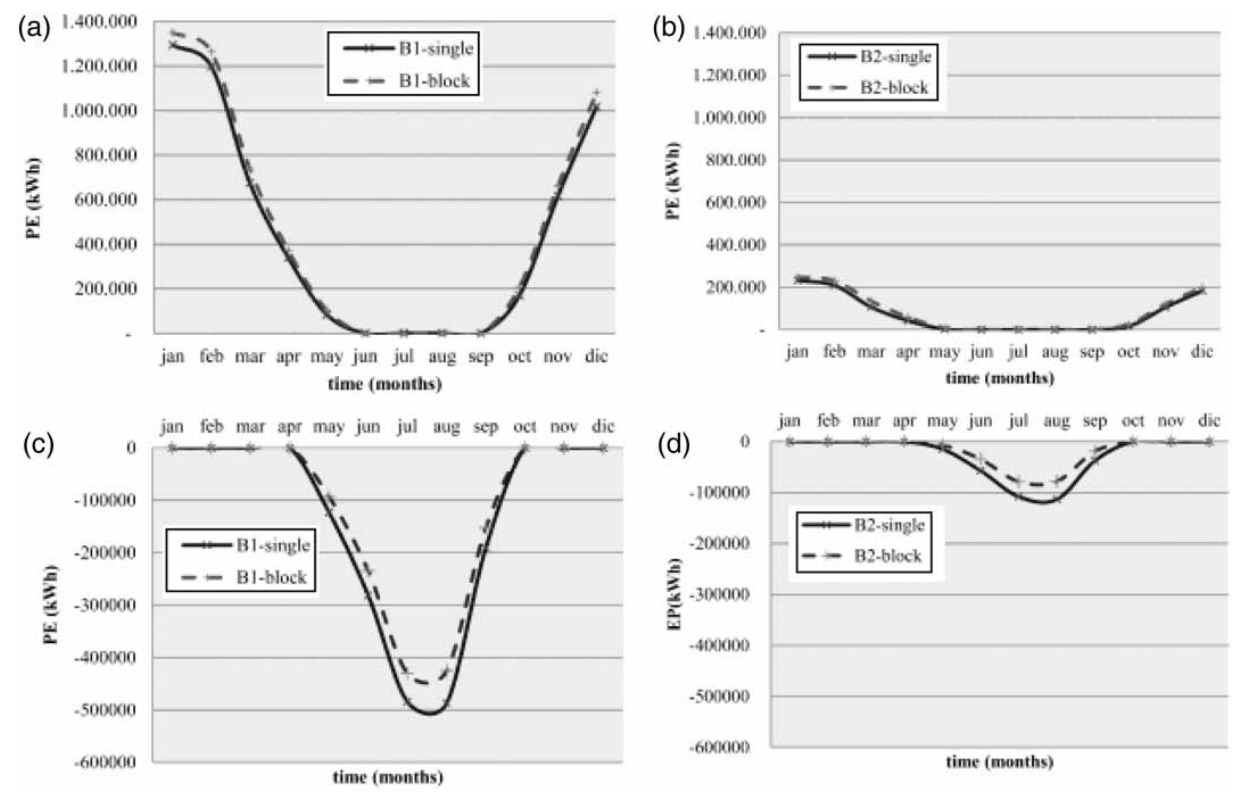

Figures 11 (a), (b), (c), (d): Year-round energy profile for the two buildings; (Left) the office one (B1) and (Right) the residential one (B2). Comparison between the stand-alone ("single") and the urban network case ("block") in terms of trend of Primary energy (kWh) for heating (11a/11b) and cooling

$(11 \mathrm{c} / 11 \mathrm{~d})$.

In more detail, the maximum difference in terms of primary energy requirement for heating between the "stand-alone building" and "network-building" scenarios, corresponds to $3.2 \mathrm{kWh} / \mathrm{m} 2$ (6 percent) in January and to $4.5 \mathrm{kWh}$ / $\mathrm{m} 2$ (26 percent) in March, for B1 and B2 respectively. Given the already mentioned lower contribution of the solar gains in the " $\mathrm{S}$ " case, higher energy needs are registered for the case of the whole urban block (See Figure 11(a) and (b)).

On the other hand, the primary energy requirement for cooling results to be higher in the stand-alone scenario for both the case-study buildings, which report a maximum difference of $5 \mathrm{kWh} / \mathrm{m} 2$ (26 percent) for B1 and $5.8 \mathrm{kWh} / \mathrm{m} 2$ (31 percent) for B2 in August (See Figures 11c and 11d).

The overall year-round IBE assessment is now carried out for both the buildings in terms of primary energy for heating and cooling. Therefore, the monthly values of the Inter-Building Effect, calculated by equation one, are reported in Figure 12.

The comparison between the IBE of the residential building with respect to the office building allows further considerations. In fact, the office building is less affected by the IBE phenomena, given its predominant internal gains which mostly determine thermal-energy behavior. Additionally, the configuration of the office building is very much higher than the surrounding constructions. This peculiar geometry makes this taller building less affected by the impact of buildings located in its close proximity.

\section{Inter-Building Effect of Varying Urban Density Levels}

In order to extend the results to other urban configurations and urban density levels, the analysis of two other New York City neighborhoods is now performed. 


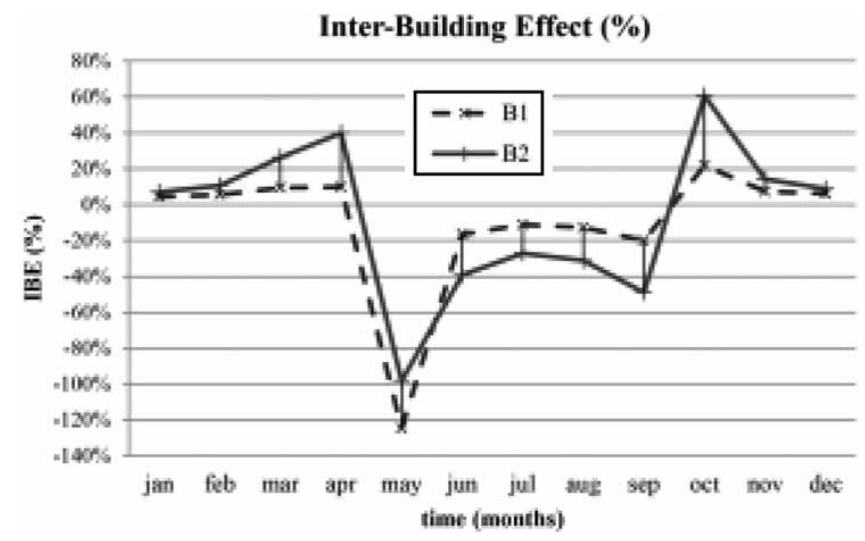

Figure 12: Year-round Inter-building effect analysis for the two case-studies, the office building (B1) and the residential building (B2).

The purpose is to investigate the IBE extent with varying urban morphology. The two neighborhoods considered in this analysis are the New York City blocks of Soho with typical low-rise buildings (i.e., non-dense urban area), and the "Theater District" (i.e., very dense urban area) which is characterized by several skyscrapers. The IBE calculation is performed for each urban layout, for both the case study buildings, and the results are reported in Figures 13a and 13b.

Consistent with the previous findings, the calculated Inter-Building Effect reveals a significant growing trend with higher urban density levels, for both B1 and B2 (See Figures 14(a) and (b)).

Table 1 points out that the Inter-Building Effect is much affected by the density level of the surrounding urban environment. In fact, the IBE values grow together with the increase of urban density both in terms of building mutual vicinity and buildings' height. This is true for both buildings, but especially for the residential one (B2), which is more affected by the IBE due to its lower height and lower internal loads. In fact, for instance, the IBE value of B2 goes from $2.5 \mathrm{kWh} /$ $\mathrm{m}^{2}$ per month (low density areas), to $3.3 \mathrm{kWh} / \mathrm{m}^{2}$ per month (dense areas), until $6.7 \mathrm{kWh} / \mathrm{m}^{2}$ per month (very density areas). As regard-ing the office building (B1), the IBE value goes from about $1.01 \mathrm{kWh} / \mathrm{m}^{2}$ per month (low density areas), to $1.97 \mathrm{kWh} / \mathrm{m}^{2}$ per month (dense areas), until $4.71 \mathrm{kWh} / \mathrm{m}^{2}$ per month (very dense areas).
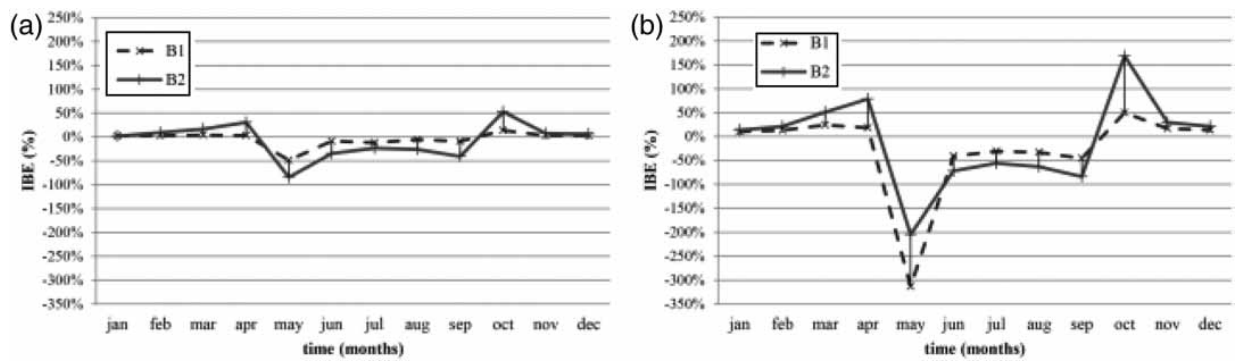

Figures 13 (a) and (b): Comparison of the year-round profile or Inter-building effect (percent) for the two case-study buildings, the office one (B1) and the residential one (B2), in the two neighborhoods:

(Left) Soho and (Right) Theater District. 

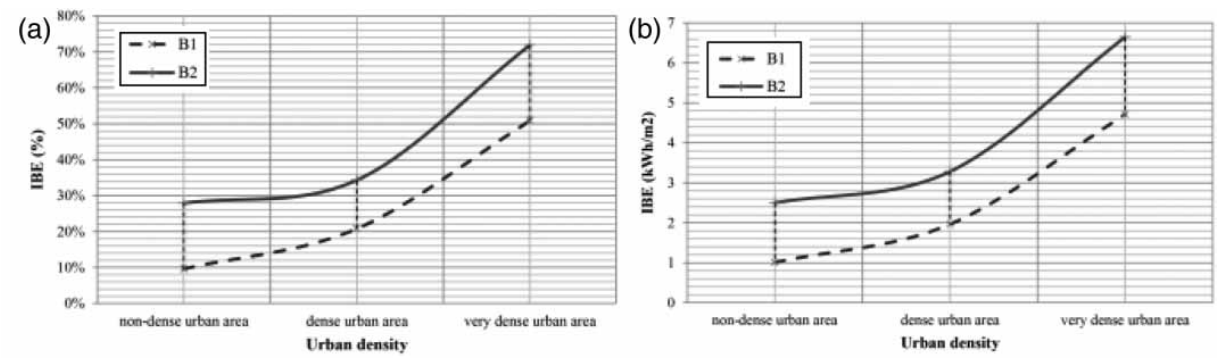

Figures 14 (a) and (b): Inter-building effect trend for the two case-study buildings, the office one (B1) and the residential one (B2), in relation to the urban density of the three considered neighborhoods;

(Left) IBE trend in percent; (Right) IBE trend in $\mathrm{kWh} / \mathrm{m}^{2}$.

Table 1. Inter-Building Effect values with the increase of urban density level, for both the case study buildings, i.e. B1 and B2.

\begin{tabular}{lrc}
\hline Urban density level & $\mathrm{IBE}_{\mathrm{B} 1}$ & $\mathrm{IBE}_{\mathrm{B} 2}$ \\
\hline Non-dense urban area & $9.6 \%$ & $27.9 \%$ \\
Dense urban area & $20.8 \%$ & $34.3 \%$ \\
Very dense urban area & $50.8 \%$ & $71.9 \%$ \\
\hline
\end{tabular}

\section{Conclusions}

In this paper, the thermal-energy assessment of two real buildings in New York City was carried out in order to evaluate the level of accuracy achievable in the prediction of building thermal-energy performance by considering the effect of the surrounding real urban context. The purpose of the research was to prove and quantify the existing Inter-Building Effect between adjacent buildings in several urban density levels, by taking into account the impact of different urban morphologies with varying construction density levels. The influential role that nearby buildings played in terms of envelope energy balance and solar gains variations was demonstrated for several realistic urban environments through year-round thermal-energy dynamic simulation. Adjacent buildings have, in fact, the effect of altering the thermal exchanges for convection and radiation; the reduction of solar gain through the openings has the advantage of reducing the energy demand for cooling, and the opposite happens during the heating season.

The comparison of the energy performance between the stand-alone buildings and the same buildings through the IBE method showed that building energy performance hugely depends on the configuration of the urban environment which could not be neglected in thermal-energy assessment of existing buildings located in an urban context. The calculated values of IBE represented the inaccuracy level in terms of overestimation and underestimation of the buildings' energy need.

The indoor thermal environment of the two buildings significantly changed when the buildings are simulated inside their real urban layout instead of as stand-alone objects. In more detail, the difference in terms of indoor operative temperature between " $\mathrm{S}$ " and " $\mathrm{N}$ " configurations varied between $1{ }^{\circ} \mathrm{C}$ and $2.5^{\circ} \mathrm{C}$ for B1 and B2 respectively. Additionally, when the analysis concerned the lower 
floors of both the buildings, the difference grew up to $2^{\circ} \mathrm{C}$ and $5^{\circ} \mathrm{C}$ for $\mathrm{B} 1$ and $\mathrm{B} 2$ respectively.

The solar gains through the external windows, which were greater in the case of buildings evaluated individually, presented a maximum difference of 24 percent in B1, and of 77 percent in B2. These differences were up to 75 percent and 78 percent when the analysis is focused on the lower floors of B1 and $\mathrm{B} 2$ respectively. The difference in terms of primary energy requirement for heating and cooling between the " $\mathrm{S}$ " and " $\mathrm{N}$ " scenarios corresponded to 6 percent and 26 percent per month for B1, and up to 26 percent and 31 percent per month for B2.

Therefore, the analysis of the change in the year-round demand for primary energy showed that the IBE phenomenon heavily affects the quality of building energy prediction, as the difference in terms of $\mathrm{kWh} / \mathrm{m} 2$ per month between the case of stand-alone buildings and buildings inside their urban network was significant, both in summer and winter, and for both the case study buildings. The lack of consideration of the Inter-Building Effect generated important differences, in both the analysis of buildings' indoor thermal behavior and primary energy requirement. Therefore, from the analysis of different urban configurations, an increasing trend of the IBE was also detected with growing urban density. In detail, the analysis showed an IBE of 9.6 percent, 20.8 percent, and 50.8 percent for the office building, and 27.9 percent, 34.3 percent, and 71.9 percent for the residential building, corresponding to the three growing levels of urban density. Additionally, the IBE was less influential for the office building, which performance is much more affected by the huge internal gains typical of office occupancy.

The analysis carried out in this paper showed that the Inter-Building Effect increases with increasing urban density. Additionally, the comparison between case study buildings with different occupancy and use showed how the IBE produces higher impacts on those buildings that are more affected by the outdoor boundary conditions, such as residential buildings. Nevertheless, the results of the dynamic simulations performed in this work showed that Inter-Building Effects could not be neglected in order to investigate building thermal-energy performance during the course of the year, in each urban context.

\section{Future Developments}

The evaluation of more representative urban climate conditions in the InterBuilding Effect analysis could represent a key future development of the research about energy efficiency of buildings located in urban areas. To this aim, the consideration of a more representative weather file in the energy model, specifically elaborated to take into account the urban heat island effect, could be useful in order to further increase the level of accuracy in the energy prediction of buildings' energy performance in an urban context. A comparison between different weather files could be performed through both dynamic simulation and IBE analysis with the purpose of evaluating whether or not the TMY climate files are representative of the real boundary condition of the buildings in dense urban environment. Interesting sensitivity analyses aimed at investigating the role of each parameter should be performed. In fact, the analysis of how local climate is able to affect the energy simulation results represents an interesting 
future task to address. In particular, the case of New York City, given its acknowledged urban heat island issue and its urban peculiarity, should be studied. In fact, the application of a more realistic climate boundary condition into the dynamic energy simulation environment might significantly change the energy requirement prediction both in terms of heating and cooling.

Therefore, further developments of this research may imply the evaluation of other factors related to a building's energy assessment such as the specific urban climate phenomena. The final aim will consist of the estimation of the overall inaccuracy imputable to the consideration of the building as stand-alone object, without taking into account (i) the real urban surrounding morphology and (ii) the local urban climate context, which represent the actual boundary conditions affecting building reliable thermal-energy performance.

\section{Acknowledgments}

The authors' acknowledgments are due to H2CU (Honors Center of Italian Universities) for supporting the Inter-Building Effect research.

\section{Notes on Contributors}

Anna Laura Pisello is a postdoctoral fellow at University of Perugia, Italy. She has been a visiting scholar at Columbia University and City University of New York (Building Performance Lab) within the framework of the activities of the H2CU Center at University of "La sapienza" in Rome, Italy.

Veronica Lucia Castaldo is a doctor of Building Engineering. She is a PhD candidate at the Department of Engineering at University of Perugia, Italy. She is involved in several international research projects concerning green buildings technologies and architecture, sustainable design, dynamic simulation of the energy requirements of buildings, urban heat islands, and local climate effects on the thermal-energy behavior of buildings. E-mail: castaldo@crbnet.it

Tiziana Poli is an associate professor in the technology of architecture at Politecnico di Milano, Italy. She is the head of the METEOLAB project housed in that university's Building and Environmental Sciences Technology Department. E-mail: tiziana.poli@polimi.it

Franco Cotana is a professor of applied physics at University of Perugia, Italy. He is the director of the Biomass Research Center and of the PhD school of Energy Engineering. E-mail: cotana@crbnet.it 


\section{Bibliography}

H. Akbari, S. Bretz, DM. Kurn, and J. Hanforn, "Peak Power and Cooling Energy Savings of High Albedo Roofs," Energy and Buildings 25 (1997) 117-126.

G. Ambrosone, S. Catalanotti, M. Matarazzo, and L. Vicari, "A Dynamic Model for the Thermal Energy Management of Buildings," Applied Energy 15: 4 (1983) 285-297.

U. Berardi, "Sustainability Assessment in the Construction Sector: Rating Systems and Rated Buildings," Sustainable Development 20 (2012) 411-424.

BS EN ISO 6946:2007, Building Components and Building Elements - Thermal Resistance and Thermal Transmittance, Calculation method.

I. Capeluto and E. Shaviv, "On the Use of 'Solar Volume' for Determining the Urban Fabric," Solar Energy 70: 3 (2001) 275-280.

J. Chen, RK. Jain, and JE. Taylor, "Block Configuration Modeling: A Novel Simulation Model to Emulate Building Occupant Peer Networks and Their Impact on Building Energy Consumption," Applied Energy 105 (2013) 358-368.

DB. Crawley, LK. Lawrie, FC. Winkelmann, WF. Buhl, YJ. Huang, CO. Pedersen, RK. Strand, RJ. Liesen, DE. Fisher, MJ. Witte, and J. Glazer, “Energy Plus: Creating a A New-Generation Building Energy Simulation Program," Energy and Buildings 33: 4 (2001) 319-331.

DB. Crawley, JW. Hand, M. Kummert, and BT. Griffith, "Contrasting the Capabilities of Building Energy Performance Simulation Programs," Building and Environment 43: 4 (2008) 661-673.

K. Dalamagkidis and D. Kolokotsa, "Reinforcement Learning for Building Environmental Control," in C. Weber, M. Elshaw, and NM. Mayer, eds., Reinforcement Learning-Theory and Applications (I-Tech Publications, 2008).

GS. Golany, "Urban Morphology and Thermal Performance," Atmospheric Environment 30: 3 (1996) 455-465.

S. Hassid, M. Santamouris, N. Papanikolaou, A. Linardi, N. Klitsikas, C. Georgakis, and DN. Assimakopoulos, "The Effect of the Athens Heat Island on Air Conditioning Load," Energy and Buildings 32 (2000) 131-141.

J. He, A. Hoyano, and T. Asawa, "A Numerical Simulation Tool for Predicting the Impact of Outdoor Thermal Environment on Building Energy Performance," Applied Energy 86 (2009) 1596-1605.

P. Heiselberg, H. Brohus, A. Hesselholt, H. Rasmussen, E. Seinre, and S. Thomas, "Application of Sensitivity Analysis in Design of Sustainable Buildings," paper presented at International Conference on Sustainable Development in Building and Environment, Chongqing, China, 25-27 September 2007.

PJ. Jones, S. Lennon, and J. Williams, “Modeling Building Energy Use at Urban Scale," paper presented at 7th International IBPSA Conference Rio de Janeiro, Brazil, 13-15 August, 2001.

R.A. Memon, D.Y.C. Leung, and L. Chunho, "A Review on the Generation, Determination and Mitigation of Urban Heat Island," Science Direct 20 (2008) 120-128.

E. Morello, V. Gori, C. Balocco, and C. Ratti, "Sustainable Urban Block through Passive Architecture," paper presented at "26nd International Conference on Passive and Low Energy Architecture," Quebec City, Canada, 22-24 June 2009.

"New York City Department of Housing Preservation \& Development," www.nyc.gov.

C.O.C. Oko, and O.B. Ogoloma, "Generation of a Typical Meteorological Year for Port Harcourt Zone," Journal of Engineering Science and Technology 6:2 (2011) 204-214.

L. Pérez-Lombard, J. Ortiz, and C. Pout, "A Review on Buildings Energy Consumption Information," Energy and Buildings 4: 3 (2008) 394-398.

A.L. Pisello, and F. Cotana, "The Thermal Effect of an Innovative Cool Roof on Residential Buildings in Italy: Results from Two Years of Continuous Monitoring," Energy and Buildings 69 (2014), 154-164.

A.L. Pisello, J.E. Taylor, X. Xu, and F. Cotana, "Inter-building Effect: Simulating the Impact of a Network of Buildings on the Accuracy of Building Energy Performance Predictions," Building and Environment 58 (2012a) 37-45.

A.L. Pisello, M. Goretti, and F. Cotana, "A Method for Assessing Buildings' Energy Efficiency by Dynamic Simulation and Experimental Activity," Applied Energy 97 (2012b) 419-429.

A.L. Pisello, V.L. Castaldo, J.E. Taylor, and F. Cotana, "Expanding Inter-Building Effect Modeling to Examine Primary Energy for Lighting," Energy and Buildings 76 (2014) 513-523.

C. Ratti, D. Raydan, and K. Steemers, "Building Form and Environmental Performance: Archetypes, Analysis and an Arid Climate," Energy and Buildings 35 (2003) 49-59.

F. Rossi, AL. Pisello, A. Nicolini, M. Filipponi, and M. Palombo, "Analysis of Retro-Reflective Surfaces for Urban Heat Island Mitigation: A New Analytical Model," Applied Energy 114 (2014) 621-631.

AH. Rosenfeld, H. Akbari, S. Bretz, BL. Fishman, DM. Kurn, D. Sailor, and H. Taha, "Mitigation of Urban Heat Islands: Materials, Utility Programs, Updates," Energy and Buildings 22 (1995) 255-265. 
K. Steemers, "Energy and the City: Density, Buildings and Transport," Energy and Buildings 35 (2013) 3-14.

F. Tronchin and K. Fabbri, "Energy Performance Building Evaluation in Mediterranean Countries: Comparison between Software Simulations and Operating Rating Ssimulation," Energy and Buildings 40 (2008) 1176-1187.

U.S. Green Building Council, http://www.usgbc.org/Default.aspx (2011).

X. Xu, J.E. Taylor, and A.L. Pisello. “Network Synergy Effect: Establishing a Synergy between Building Network and Peer Network Energy Conservation Effects," Energy and Buildings 68 (2014) 312-320. 